\title{
Trabajo Social, capitalismo y el mundo unipolar. Comentario a la ponencia central de James Midgley
}

\author{
Social Work, capitalism and the unipolar world. \\ Comment to James Midgley's central conference
}

\section{PhD. Ana Elizabete Mota}

Ana Elizabete Mota es profesora del Departamento de Servicio Social de la UFPE (Universidad Federal de Pernambuco) Av. Prof. Moraes Rego, 1235 - Prédio da Reitoria - CEP.50.670-901 Cidade Universitária - Recife - PE - Brasil; bmota@elogica.com.br

\begin{abstract}
Resumen
De acuerdo a la autora, Midgley define el campo de las relaciones internacionales de poder como un vector analítico esencial para el análisis del asunto de la desigualdad y de los mecanismos utilizados para enfrentarlas, entre ellos, la intervención del Servicio Social. Sin embargo ella insiste en que las desigualdades sociales son inherentes al desarrollo del capitalismo y que para revertir $u$ oponerse al dominio global del capitalismo que se expresa en las iniciativas económicas y en sus disposiciones políticas, se impone la conciencia de las desigualdades que son inherentes a la formación y constitución de las clases sociales.
\end{abstract}

Palabras claves (Mundo unipolar, capitalismo, clases sociales, desigualdades)

\begin{abstract}
According to the author, Midgley narrows the field of international relations of power as an essential analytical dimension to analyze inequality and the mechanisms used to face it, including the intervention of Social Service. But Mota insists that social inequalities are inherent to the development of capitalism and to reverse or oppose the domination of global capitalism, expressed in economic initiatives and in its political provisions, it is needed to impose awareness about inequalities through training and formation of social classes.
\end{abstract}

Key words (Unipolar world, capitalism, social class, inequalities)

Me gustaría saludar a todos los participantes del $33^{\circ}$ Congreso Mundial de Escuelas de Trabajo Social, y agradecer la invitación de la Comisión Organizadora, en especial a la Coordinadora académica del evento, Teresa Matus, por la oportunidad de dialogar con el Servicio Social mundial. Lo hago a nombre mío, de mi Universidad, la Universidad Federal de Pernambuco, y de la Asociación Brasileña de Enseñanza e Investigación de Servicio Social, que se hace representar en este Congreso.

También aprovecho la oportunidad para felicitar a los demás integrantes de este panel, en particular al conferencista, profesor James Midgley, cuya exposición será el objeto de mis comentarios.

No podría ser más oportuno el tema de esta sesión, quizás uno de los más estratégicos para alimentar el debate y las iniciativas que estamos presenciando en este Congreso.

Vuelvo al objetivo de mi participación en este panel para expresar mi acuerdo con los términos generales del debate presentado por el Profesor Midgley, así como con el estimulante desafío que nos hace al proponer la creación de una agenda política, teórica y académica para el Servicio Social mundial.

$\mathrm{Al}$ alero de la denuncia de la unipolaridad norteamericana, cuya autorepresentación de gobierno del mundo nos remite al concepto de nación imperialista, el profesor delimita el campo de las relaciones internacionales de poder como un vector analítico esencial para el análisis del asunto de la desigualdad y de los mecanismos utilizados para enfrentarlas, entre ellos, la intervención del Servicio Social. 
En el desarrollo de su conferencia el Profesor destaca tres puntos fundamentales que profundizó y analizó a lo largo de su exposición:

1. La necesidad de hablar sobre la desigualdad más allá de una perspectiva cuantitativa, economicista y monetarista problematizándola desde una perspectiva que llamó multicultural y sociológica;

2. La importancia de darle un enfoque más amplio a la desigualdad, tratándola en el contexto de las relaciones internacionales de poder, cuyas macro-determinaciones inciden en la forma en que diferentes estados-naciones incorporan tanto la relación entre crecimiento económico y desigualdad como la relación entre poder global y desigualdades regionales, nacionales y locales;

3. La ineludible necesidad de ampliar el horizonte y los objetos de búsqueda/investigación y conocimiento en el Servicio Social, incorporando estudios e intervenciones cuyas perspectivas sobrepasen la comprensión de las desigualdades sociales en términos de inequidad en el ingreso y/o de manifestación de formas de opresión étnicas, de género y culturales, y las instalen al interior de las relaciones internacionales de poder. Se trata de identificar la forma en que esas relaciones afectan directa o indirectamente las condiciones de vida y los derechos humanos y sociales de millares de personas en los más diversos países, y de conocer los mecanismos vigentes de intervención social, muchos de los cuales son implementados por trabajadores sociales de todo el mundo.

Luego de identificar los problemas y analizar las tendencias teóricas e ideo-políticas que informan el debate sobre la unipolaridad, en particular lo que aparece expresado en la "paz americana", el Profesor Midgley concluye su exposición defendiendo la multi-lateralidad, la cooperación internacional, los derechos humanos y la justicia internacional, ofreciendo indicaciones que me parecen muy importantes:

1. La revelación de los temas presentes en la agenda unipolar, entre otros, los que están siendo incorporados por los organismos financieros internacionales tales como el Banco Mundial, el FMI y la OMC, y que afectan en forma directa a los sistemas de protección social, educación, políticas ambientales y de género, etc., como condición para construir nuevos mecanismos de contrapoder internacional;

2. La conciencia del papel de la ideología unipolar y de las poderosas fuerzas globales predominantes, en particular la ofensiva del pensamiento único que se expresa en la ideología neoliberal y en las coercitivas estrategias de poder;

3. La necesidad de manifestaciones públicas contra el brutal ejercicio del poder global, desafiando a los poderosos locales e internacionales;

4. La formación de alianzas con organizaciones internacionales progresistas y con movimientos sociales con objeto de abordar la desigualdad en el mundo.

Aunque concuerdo con la problemática y las propuestas sugeridas, pienso que a esas afirmaciones debemos agregar otros problemas y asuntos, lo que haré a continuación:

- Parto del principio de que las condiciones de vida y de trabajo de millones de personas que viven al margen de la producción y del beneficio de la riqueza producida socialmente, tanto en los principales países como en los países de la periferia, revelan que las desigualdades sociales son inherentes al desarrollo del capitalismo.

- El modo de producir, distribuir y acumular los bienes materiales y la riqueza es un producto histórico, resultado de la acción de hombres y mujeres, que al aportar con la reproducción de su propia vida reproducen las relaciones sociales. Son hombres y mujeres que hacen la historia, si bien bajo condiciones y relaciones determinadas.

- El capitalismo, en el curso de su desarrollo histórico, junto con instituir la acumulación de la riqueza, produjo el fenómeno de la extrema pobreza. Tal como podemos constatar, ya en el siglo XIX estaba arraigado el problema que vendría a desafiar el siglo XXI: la indiscutible tendencia a la exclusión de los procesos productivos y del acceso a los bienes materiales y culturales socialmente producidos.

- Lo que diferencia la problemática y la programática de la situación anterior respecto de la actual es el horizonte expansivo del capitalismo, con la brutal reducción de la mano de obra (en los procesos de trabajo y producción), la subordinación de la producción material a los imperativos del capital financiero, los cambios 
en la intervención social del Estado y el acento de este proceso en las luchas en la historia de la clase trabajadora.

Si en el periodo expansivo de la post-guerra el Estado era el que mediaba la acumulación a través de la intervención social, hoy en día éste gestiona la financierización ${ }^{1}$ y le entrega a la sociedad y a sus organizaciones la responsabilidad de encontrar formas "creativas" de abordar el problema social, depositando en la ayuda, en la solidaridad interpersonal, en el voluntarismo personal y empresarial y en el trabajo social, la única posibilidad de intervención social. Todas estas son efímeras, ocasionales, y surgen en regímenes de excepción o de emergencia. Del mismo modo, transforma aquellos que fueran los pilares de sustentación de los sistemas mundiales de protección social en servicios comerciales o en negocio, despojando con esto a los usuarios de los servicios públicos y colectivos de su condición de sujetos con derechos y transformándolos en genéricos ciudadanos consumidores.

Así las cosas, el panorama mundial, subordinado a las relaciones internacionales de poder y a una capacidad sin precedentes de concentración de la riqueza en pocas manos, deja patente la existencia de problemas que afectan en forma severa el modo de ser y de vivir de los trabajadores: el desempleo estructural, la crisis del trabajo asalariado, la desarticulación del estado de bienestar, la cancelación de los derechos sociales, asuntos que afectan el tenor ideológico de sus luchas sociales. Sí, ya que para revertir u oponerse al dominio global del capitalismo que se expresa en las iniciativas económicas y en sus disposiciones políticas, se impone la conciencia de las desigualdades que son inherentes a la formación y constitución de las clases sociales.

Más que las normas y disposiciones económicas, lo que el nuevo imperialismo instala en el mundo es la construcción de una hegemonía plasmada por la difusión de culturas y valores de una determinada clase: la de los que acumulan riqueza y poder a costa del trabajo de los millones de hombres, mujeres y niños de todo el mundo.

Calificado por muchos como un periodo en el que el trabajo perdió su centralidad o como un periodo en el cual el capitalismo dejó de tener miedo, el hecho es que estas últimas dos décadas son el escenario de un proceso de restauración capitalista asentado en un doble movimiento: la redefinición de las bases de la economía del mundo a través de la reestructuración productiva y de los cambios en el mundo del trabajo; y la ofensiva ideo-política necesaria para la creación del predominio del gran capital, que se evidencia en el surgimiento de un nuevo imperialismo, característico de esta nueva fase del capitalismo.

Según Harvey (2003), el predominio ha sido ejercido por Estados Unidos mediante el uso de estrategias que combinan la coerción y el consenso y lo hace como "un estado dominante que dirige un sistema de Estados en una dirección determinada, y al hacerlo, es percibido mayoritariamente como un gobierno mundial, abocado a promover el interés general". Al delimitar la ideología de sus opositores establecen la suya como ideología universal.

En la fase actual, los capitales que circulan en los círculos financieros provienen del sector productivo, pero es el capital financiero el que se nutre de la transferencia de la riqueza en un círculo muy propio. Los resultados son el desempleo y el empobrecimiento de millones de personas.

En oposición a la acumulación expandida que marcó la primera mitad del siglo XX, lo que está en proceso de consolidación es la acumulación por despojo bajo el comando de los países ricos. El principal vehículo de esta acumulación por usurpación ha sido la apertura forzada de mercados en todo el mundo mediante presiones institucionales ejercidas por medio del FMI o de la OMC.

Este proceso va desde el patentar las investigaciones genéticas, la mercantilización de la naturaleza a través del derecho a contaminar, hasta la privatización de los bienes públicos y la transformación de los servicios sociales en negocios, como viene ocurriendo con la salud, la previsión social y la educación. Se continúa con la ampliación de los fondos de pensión, dando origen a lo que Peter Druck llama capitalismo de los trabajadores o fin del capitalismo, puesto que la propiedad de los fondos es de los trabajadores, haciendo que los procesos de financierización y privatización estén en manos de estas instituciones que concentran el mayor volumen de activos disponibles en el mundo. Los trabajadores se transforman en accionistas mayoritarios de las mayores corporaciones mundiales, así como en ejecutivos del capital financiero.

1 La financierización consiste en priorizar los capitales financieros y comerciales sobre los industriales (N. Traductor). 
También implica la degradación del medio ambiente, con el aumento de la industria de los desechables y con la producción de mercancías con caducidad programada, generando una sociedad de basura y de productos desechables.

La mercantilización de la esfera de la reproducción también es uno de los nuevos signos de la actual etapa y repercute en dos aspectos: a) la expropiación y mercantilización de actividades domésticas y privadas no mercantiles de las que son ejemplo los servicios de cuidado del hogar y los cuidadores sociales; b) y la sobre explotación de las familias, particularmente de las mujeres, en los países periféricos que, asumen como parte de sus actividades domésticas y bajo su responsabilidad, y a costa de hacer más precarias sus condiciones de vida, un conjunto de actividades que deberían ser públicas.

También en el ámbito del trabajo hay cambios substantivos, ya sea bajo una nueva versión de antiguas formas de trabajo, como la producción de partes, en el hogar, etc., o bien instituyendo nuevos procesos de trabajo, externalizando y desterritorializando parte del ciclo productivo o construyendo nuevos modos de cooperación, donde se adaptan en un mismo proceso productivo, actividades que implican altas tecnologías y la absoluta precariedad.

La ofensiva para asegurar la reproducción de esos procesos pasa por dos mecanismos: la reforma del Estado y la definición de estrategias que deben ser formadoras de una nueva cultura y formas de convivencia. En esa nueva convivencia se reconsidera al ciudadano con derechos, convirtiéndolo en un supuesto ciudadano consumidor; el antiguo trabajador asalariado se considera un emprendedor; el desempleado pasa a integrar la clientela de los programas de ingreso mínimo; y los trabajadores subcontratados se transforman en socios de los grandes negocios mediante los fondos de pensión y de los mecanismos de co-gobierno. Además, las relaciones locales y de vecindad se consideran comunitarias y solidarias, difundiendo la idea de componer una identidad asociativa, solidaria y cooperativa. También se observan formas de despolitización de las acciones colectivas, tratadas ahora como mecanismos de empoderamiento. Nos preguntamos: ¿Empoderamiento de quién? ¿Para qué?
En este panorama, el gran capital desea que los lugares ocupados por las clases trabajadoras en los procesos de producción y reproducción social se separen cada vez más de su convivencia de clase, fragmentándosela, y a veces, confrontando sus intereses.

Al la vez que el proceso de mundialización consigue articular y reunir los capitales de todas partes del mundo, fragmenta las identidades y las necesidades de aquellos que viven de su trabajo. Es la razón de que sea necesario crear una interfase con el movimiento antiglobalización -anticapitalista y anti-imperialista con acento en la tensión entre lo global y lo local, en una perspectiva de clases, como la única manera de resistir y revertir el proceso social en curso.

Eso no es tarea exclusiva de los asistentes sociales, si bien como trabajadores sociales que somos, como profesionales reconocidos socialmente por la utilidad de nuestro trabajo, tenemos la obligación, cada uno desde su lugar y desde su país, de no desconocer este proceso. Es necesario tener claro que los mecanismos de enfrentamiento y superación de las desigualdades sociales deben considerarse en dos dimensiones: 1) la que apunta al enfrentamiento a través de la lucha por la emancipación política -el campo del derecho, del acceso universal, del reconocimiento público y civil de la condición del ciudadano- 2) la que percibe su superación a través de la búsqueda de la emancipación humana de los pueblos, cuya estrategia puede ser la internacionalización de las luchas de los trabajadores, proceso para el cual tenemos contribuciones, teorías, políticas y prácticas para ofrecer.

Es en esta atmósfera que están puestos los desafíos del Servicio Social mundial. En primer lugar, un supuesto para todos nosotros: si se confunde la esencia con la apariencia, toda investigación sería innecesaria. En segundo lugar, investigar nuestra práctica docente de una condición de trinchera teórica, académica y de formación y capacitación de las nuevas generaciones de profesionales, respetando las diferencias, pero sin renunciar a la posibilidad de ser profesionales críticos, formadores de cultura y protagonistas de la construcción de una sociedad distinta. Las sugerencias del Profesor Midgley son un buen comienzo para este proyecto. Gracias. 